\title{
Treatment of critical lower limb ischemia using a hybrid technique
}

\section{Tratamento de isquemia crítica de membro inferior com técnica híbrida}

Ricardo Wagner da Costa Moreira', Pedro Victor Alcântara da Costa², David Domingos Rosado Carrilho³

\begin{abstract}
Critical ischemia of a lower limb is a condition that threatens its viability and must be treated promptly to avoid major amputation. Revascularization is the most effective treatment method and is performed using surgical or endovascular techniques. For patients with thoracoabdominal aortic aneurysms, combining these two approaches into a "hybrid technique" makes it possible to treat patients who could not be adequately treated by either technique in isolation. We report on a case of lower limb critical ischemia treated using a combination of surgery and endovascular techniques, in an application of the hybrid technique in a different arterial bed.
\end{abstract}

Keywords: arterial occlusive diseases; vascular surgery procedures; angioplasty.

\begin{abstract}
Resumo
A isquemia crítica de membro inferior é uma condição que constitui uma ameaça à viabilidade do membro e deve ser prontamente tratada para evitar uma amputação maior. A revascularização é o tratamento mais eficaz, podendo ser por técnica cirúrgica ou endovascular. Nos pacientes com aneurisma toracoabdominal da aorta, a combinação das duas técnicas, denominada técnica híbrida, permite ampliar a possibilidade de tratamento de pacientes que não seriam adequadamente tratados por nenhuma das duas técnicas isoladamente. Descrevemos o tratamento de uma isquemia crítica de membro inferior utilizando a combinação de cirurgia convencional e tratamento endovascular, também se constituindo, assim, em uma técnica híbrida, mas em outro território arterial.
\end{abstract}

Palavras-chave: arteriopatias oclusivas; procedimentos cirúrgicos vasculares; angioplastia.

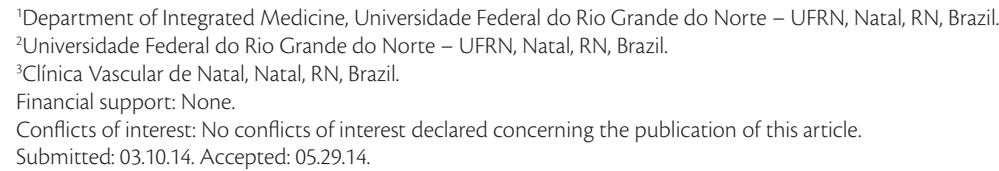




\section{INTRODUCTION}

Critical lower limb ischemia (CLLI) is a condition in which patient a presents a clinical status of pain at rest or has trophic ulcers, and is a clinical presentation linked with a high risk of loss of the affected limb. In developed countries, incidence is estimated at 50 to 100 cases in 100 thousand inhabitants per year. ${ }^{1}$ CLLI is therefore clearly responsible for increasing morbidity and mortality and consumes considerable social and healthcare resources. ${ }^{1}$

The ideal treatment for CLLI is revascularization, which can be accomplished using conventional surgical techniques (bypass) or endovascular methods (angioplasty). The first option prioritizes long term anatomic patency and clinical durability, but is linked with greater morbidity and mortality and demands considerable financial expenditure. The endovascular approach, in turn, offers lower morbidity and mortality and reduced expenditure, can be performed more quickly, requires a shorter length of hospital stay and also preserves collateral circulation, making it possible that symptoms will not return in the event of occlusion at the angioplasty site. ${ }^{1}$ In general, patients with TASC A and B lesions exhibit better results after angioplasty, while patients with TASC C and D lesions respond better to bypass surgery. $^{2}$

Bypass surgery is an excellent option for limb salvage in patients who are good candidates for surgical revascularization. However, the subset of good candidates for the procedure is considerably restricted by prohibitive comorbidities, local skin conditions, absence of suitable vessels for grafting, patient body type (obesity) and inadequate distal bed for revascularization. ${ }^{3}$

It is becoming ever more common to treat patients with thoracoabdominal aortic aneurysms using a hybrid technique. In other words, the conventional surgical technique and the endovascular techniques are used in combination, with revascularization of visceral branches originating from the aneurysm and placement of an endoprosthesis. The hybrid technique therefore makes it possible to extend the indications for aneurysm repair, thereby benefiting a larger number of patients.

In an analogous manner to utilization of a hybrid technique to repair a thoracoabdominal aortic aneurysm, we employed a combination of a conventional surgical technique (bypass) and an endovascular technique (angioplasty) to treat a patient with CLLI. The case is described below.

The Research Ethics Committee at the Onofre Lopes University Hospital, at the Universidade Federal do Rio Grande do Norte has ruled that articles in the case report format only require informed consent in writing from the patient, which was provided in this case.

\section{CASE REPORT}

The patient was a 72-year-old female diabetic with hypertension and obesity. She had began to suffer pain in the right foot at rest approximately 30 days previously. She claimed not to have suffered from claudication previously, but walking was restricted to her home and its immediate surroundings. Her pain improved when the leg was suspended. Physical examination revealed a low temperature right foot, cyanosis with transient blanching and no sensory or motor deficits. The femoral pulse was present $(+4 /+4)$, but popliteal and distal pulses were absent. The patient had bilateral CEAP C4 varicose veins and dermatofibrosis.

Arteriography showed evidence of femoropopliteal occlusion and multiple stenoses and occlusions in the posterior tibial, with total occlusion at the mid third; multiple stenoses and segmental occlusions in the tibial anterior artery, with total occlusion of the distal third of the leg, and multiple stenoses of the mid segment of the fibular artery, which was responsible for refilling of the dorsalis pedis artery and consequent irrigation of the foot. The initial segment of the dorsalis pedis artery also exhibited stenosis. Doppler ultrasonography showed that the right internal saphenous vein only had adequate diameter for use as a graft up to the mid third of the leg.

The patient was taken to theater and underwent an infrapatellar femoropopliteal bypass, using the ipsilateral internal saphenous vein, reversed in anatomic position. Before arterial clamping, 5,000 UI of heparin were administered, and proximal and distal end-to-side anastomoses were constructed using 6-0 polypropylene thread. After closure of the incisions, the patient was transferred to the Hemodynamics Department, and sterile preparation of the right lower limb was conducted once more. The lower incision in the thigh was reopened, exposing the saphenous vein used for the bypass. The saphenous vein was then punctured under direct view and a $4 \mathrm{~F}$ introducer was fitted (Figure 1). Another 5,000 UI dose of heparin was administered. Arteriography at this point confirmed the lesions found during the previous examination (Figure 2).

The lesions in the fibular artery were traversed with a 0.014 " Shinobi ${ }^{\circledR}$ guidewire (Cordis, Miami, United States) and the guidewire tip was placed 


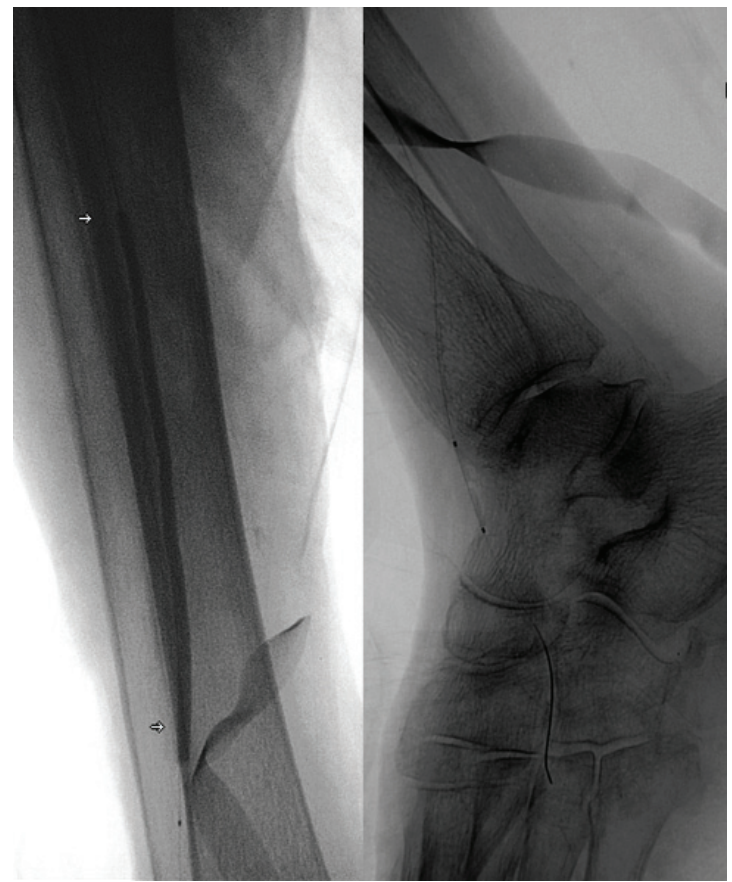

Figure 1. Angioplasty of the fibular artery with an Amphirion $3 \times 150 \mathrm{~mm}$ balloon catheter and the dorsalis pedis artery with an Amphirion $1.5 \times 20 \mathrm{~mm}$ balloon catheter.

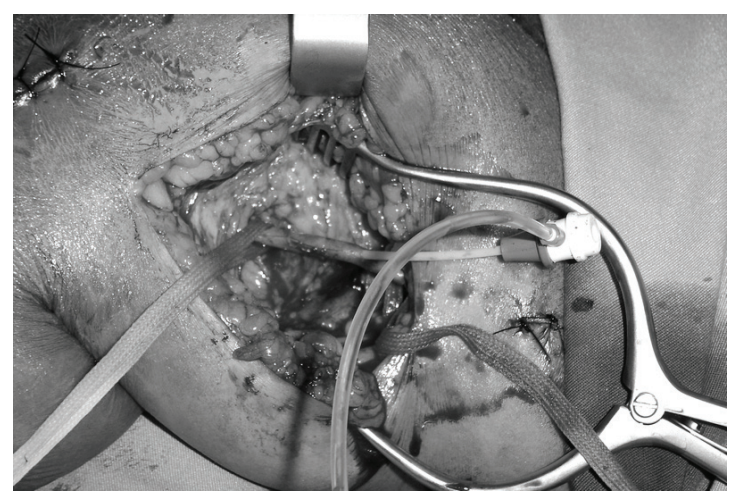

Figure 2. Access via direct puncture of the vein used for the bypass and placement of the $4 \mathrm{~F}$ introducer.

in the distal segment of the dorsalis pedis artery. Angioplasty of the fibular artery was then conducted using an Amphirion $3 \times 150 \mathrm{~mm}$ balloon catheter (Invatec) and angioplasty of the dorsalis pedis artery was conducted using an Amphirion $1.5 \times 20 \mathrm{~mm}$ balloon catheter (Invatec) (Figure 3). The result in the fibular artery was satisfactory, but significant recoil was observed in the dorsalis pedis artery, and so further dilation was applied using an Amphirion $2 \times 40 \mathrm{~mm}$ balloon catheter (Invatec), achieving a good final appearance (Figures 4 and 5).

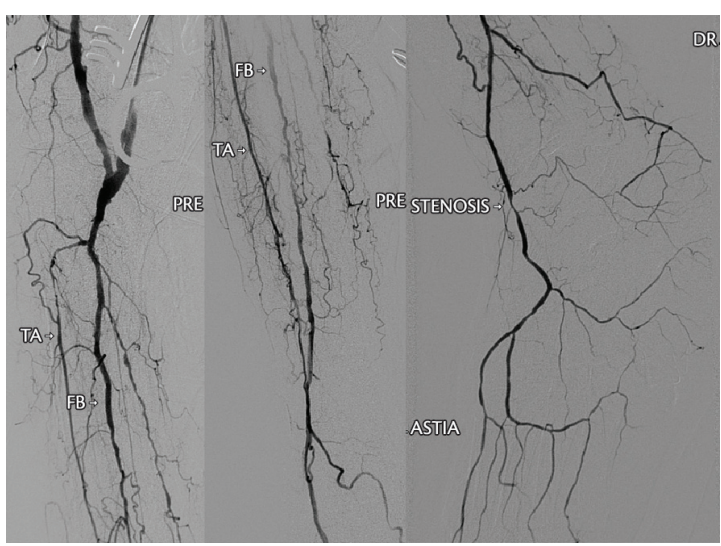

Figure 3. Pre-angioplasty angiography showing the distal anastomosis of the bypass and the lesions to distal arteries described in the text.

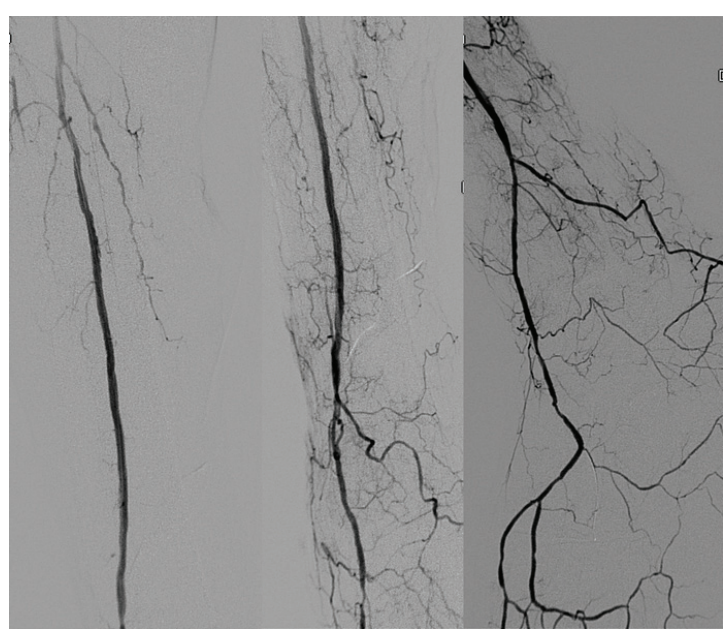

Figure 4. Final appearance of fibular and dorsalis pedis arteries, showing residual stenosis in the dorsalis pedis.

After the final control arteriography, the introducer was withdrawn and the orifice in the vein closed using 6-0 polypropylene thread sutures, before closure of the wound in the skin.

The patient progressed well, her temperature and perfusion regained normal characteristics, her pedal pulse was once more present and her pain at rest was eliminated.

\section{DISCUSSION}

Patients with CLLI can require amputations if revascularization cannot be accomplished. Among high risk patients, mortality within 30 days of amputation can range from 4 to $30 \%$, with morbidity from 20 to $37 \%$, because many of these patients suffer sepsis and progressive renal failure. ${ }^{4}$ Fewer than two thirds of patients with below the knee amputations and fewer than half of above the knee 


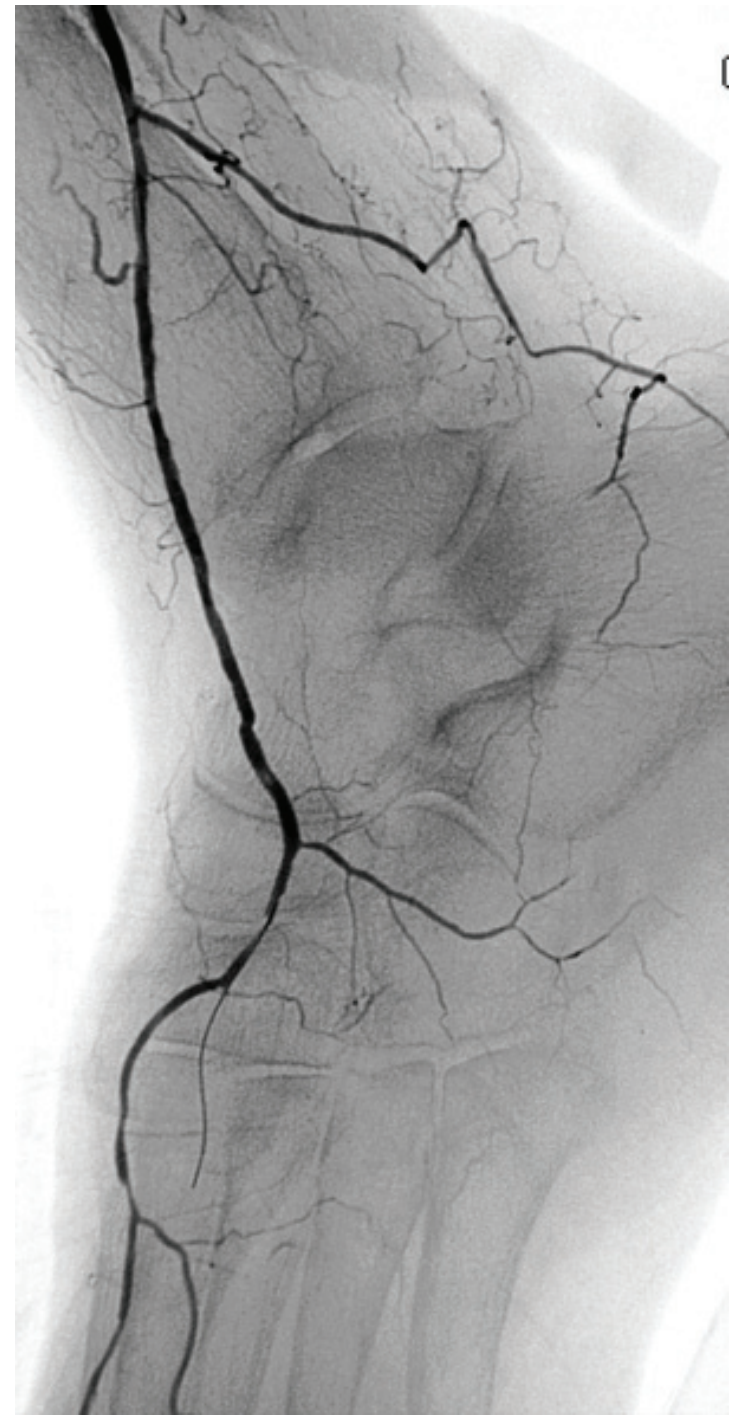

Figure 5. Final appearance of dorsalis pedis artery after angioplasty with Amphirion 2×40 mm balloon catheter.

amputation patients achieve successful rehabilitation. Additionally, fewer than $50 \%$ of patients achieve complete mobility after amputation. Furthermore, the clinical and economic costs of primary amputation as standard treatment are very high when compared with the cost of revascularization and salvage of the limb. Revascularization therefore offers many advantages: significant rates of limb salvage, lower morbidity and mortality rates 30 days after the procedure, improved functional status and quality of life for patients, better profitability and increased long-term survival. ${ }^{4}$

Bypass surgery is a revascularization option that offers good rates of technical and clinical success and good rates of patency. However, this surgery may not be possible in the presence of limiting factors, such as the need for a venous or prosthetic vessel with adequate length and diameter, good patient surgical risk and appropriate skin conditions at the site of access.

The endovascular technique (angioplasty) is becoming more widely used for lower limb revascularization because it is much less invasive and does not suffer from the factors limiting bypass surgery. It can also be used with high surgical risk patients.

The results of the BASIL Trial ${ }^{1}$ shows that patients who were treated first using bypass surgery had oneyear amputation-free survival of $68 \%$ and three-year amputation-free survival of $57 \%$. Patients initially treated with angioplasty had one-year survival of $71 \%$ and three-year survival of $52 \%$. Therefore, on the basis of medium term outcomes, patients with CLLI who have infrainguinal atherosclerosis and offer adequate technical conditions for both techniques can be treated with either method, depending on individual patient characteristics and the medical team's experience with the respective techniques.

Low mortality rates have been reported for CLLI patients managed using angioplasty. Although bypass surgery results in better primary and secondary patency than angioplasty, rates of limb salvage are similar for both treatments, showing the potential of angioplasty for treatment of CLLI. ${ }^{5}$

According to Balaz et al., ${ }^{6}$ one therapeutic option for CLLI with multi-segment arterial disease is to combine the endovascular procedure with revascularization surgery, using a hybrid technique.

In an analogous manner, it is becoming ever more common for patients with thoracoabdominal aortic aneurysm (TAA) to be treated using hybrid procedures. Conventional surgical techniques are combined with endovascular techniques to treat TAA, taking advantage of the best of what each technique has to offer, thereby extending the limits of the indications for TAA repair.

Our patient presented with critical ischemia (pain at rest) of the right lower limb. Arteriography showed femoropopliteal obstruction and multiple lesions in distal arteries, with the fibular artery playing a major role in supplying the leg. There was also stenosis of the dorsalis pedis artery. One option initially considered, which generally offers good results, was to perform a femoral-pedal bypass. ${ }^{7}$ However, the local skin conditions of the foot and the distal third of the leg were inadequate because of chronic venous insufficiency and obesity ${ }^{8}$ and the patient's 
saphenous veins were not long enough to reach this point, so this option had to be ruled out.

A femoropopliteal infrapatellar bypass would undoubtedly have increased perfusion pressure in the distal arteries, but probably not sufficiently to achieve adequate revascularization because of the presence of stenoses and segmental occlusions in these arteries. These stenoses and segmental occlusions could have been treated using angioplasty, but the femoropopliteal occlusion meant that there was no vascular access to this territory.

The solution chosen was to combine the two procedures into a hybrid technique. Initially an infrapatellar femoropopliteal bypass was constructed using the reversed saphenous vein, which then served as access for placement of an introducer. This, in turn, enabled successful angioplasty of the fibular artery and the dorsalis pedis artery. Notwithstanding, even if the angioplasty had not been successful, because of difficulties caused by the lesions themselves, the bypass would not have been in vain, since it would still increase distal perfusion pressure.

In the event, by using a combination of conventional surgery and the endovascular technique in a hybrid method it was possible to accomplish adequate revascularization of the lower limb, saving it.

\section{REFERENCES}

1. Adam DJ, Beard JD, Cleveland T, et al. Bypass versus angioplasty in severe ischaemia of the leg (BASIL): multicentre, randomised controlled trial. Lancet. 2005;366(9501):1925-34. http://dx.doi. org/10.1016/S0140-6736(05)67704-5. PMid:16325694

2. Norgren L, Hiatt WR, DormandyJA, Nehler MR, Harris KA, Fowkes FG. Inter-Society Consensus for the Management of Peripheral Arterial Disease (TASC II). J Vasc Surg. 2007;45(1, Suppl S):S5-67. http://dx.doi.org/10.1016/j.jvs.2006.12.037. PMid:17223489

3. Bosiers M, Deloose K, Moreialvar R, Verbist J, Peeters P. Current status of infrapopliteal artery stenting in patients with critical limb ischemia. J Vasc Bras. 2008;7(3):248-55. http://dx.doi.org/10.1590/ S1677-54492008000300010.
4. Allie DE, Hebert C), Lirtzman MD, et al. Critical limb ischemia: a global epidemic.A critical analysis of current treatment unmasks the clinical and economic costs of CLI. Eurolntervention. 2005;1(1):75-84. PMid:19758881.

5. Romiti $M$, Albers $M$, Brochado-Neto FC, Durazzo AE, Pereira CA, De Luccia N. Meta-analysis of infrapopliteal angioplasty for chronic critical limb ischemia. J Vasc Surg. 2008;47(5):975-81. http://dx.doi.org/10.1016/j.jvs.2008.01.005. PMid:18372148

6. Balaz P, Rokosny S, Koznar B, Adamec M. Combined infrainguinal reconstruction and infrapopliteal intraluminal angioplasty for limb salvage in critical limb ischemia. Interact Cardiovasc Thorac Surg. 2009;9(2):191-4. http://dx.doi.org/10.1510/ icvts.2009.204867. PMid: 19470500

7. Dorweiler B, Neufang A, Schmiedt W, Oelert H. Pedal arterial bypass for limb salvage in patients with diabetes mellitus. Eur J Vasc Endovasc Surg. 2002;24(4):309-13. http://dx.doi.org/10.1053/ ejvs.2002.1735. PMid:12323173

8. Löfberg AM, Karacagil S, Ljungman C, et al. Distal percutaneous transluminal angioplasty through infrainguinal bypass grafts. Eur J Vasc Endovasc Surg. 2002;23(3):212-9. http://dx.doi.org/10.1053/ ejvs.2001.1584. PMid:11914007

Correspondence Ricardo Wagner da Costa Moreira Av. Campos Sales, 759, Apto. 800 - Tirol CEP 59020-300 - Natal (RN), Brazi E-mail: ricardowcm@yahoo.com.br

Author information RWCM - Vascular surgeon at Clínica Vascular de Natal, and Assistant professor, Universidade Federal do Rio Grande do Norte (UFRN). PVAC - Medical student, Universidade Federal do Rio Grande do Norte (UFRN) DDRC - Vascular surgeon at Clínica Vascular de Natal.

Author contributions Conception and design: RWCM Analysis and interpretation: RWCM, PVAC, DDRC Data collection: RWCM, PVAC Writing the article: RWCM, PVAC Critical revision of the article: RWCM, PVAC, DDRC Final approval of the article*: RWCM, DDRC, PVAC Statistical analysis: N/A Overall responsibility: RWCM Financial support: None.

*All authors have read and approved of the final version of the article submitted to I Vasc Bras. 